Please note: this is an author-created version of the final publication. The final publication is available at www.springerlink.com/content/v380051302688081/

Please cite this article as follows:

Adams, M., Walker, C. and O'Connell, P. (2011) Invisible or Involved Fathers? A Content Analysis of Representations of Parenting in Young Children's Picturebooks in the UK. Sex Roles, Vol. 65, 3-4, 259-270, DOI: $10.1007 / \mathrm{s} 11199-011-0011-8$

\title{
Invisible or involved fathers? A content analysis of representations of parenting in young children's picturebooks
}

\author{
Matthew Adams ${ }^{1}$, Carl Walker and Paul O'Connell \\ University of Brighton
}

\begin{abstract}
Although sex-role stereotyping in children's books is a consistent focus of research, the study of the gender role stereotyping of parenting in children's media is less common, despite a developing academic interest in the changing social meanings of fathering and mothering in contemporary societies. Previous analysis, though scarce, has suggested that fathers are under-represented in general and when present, are less likely to be seen expressing affection towards, or caring for, children than mothers. In this study we revisited representations of mothers and fathers in children's picturebooks, updating previous research via numerous methodological developments. A content analysis of a representative sample of all young children's picturebooks featuring representations of parents was undertaken. The results offered qualified support for previous research, and found additional differences in terms of presence around the home, emotional expression, appearances with, and contact with, children. The significance of the finding of no difference between parental sex in terms of childcare activity and explicit nurturing activity is considered in terms of a possible shift from invisible to involved fatherhood.
\end{abstract}

Keywords: children's literature; fathers; gender stereotypes; mothers; parents; picturebooks

\section{Introduction}

'From fairy tale to adventure story, what society provides for its children reflects those values which it interprets as central to its continuity. In this way, children's books can be seen as a part of the text of history and are a significant part of the discourse of how society is moulded' (Lees and Senyard 1985: 174).

Developmental psychology suggests that it is between the ages 3-5 that children commence the practice of identifying and differentiating between sexes and categorising them according to culturally prevalent stereotypes (Powlishta, Serbin, \& Moller 1993). It follows

\footnotetext{
${ }^{1}$ Lead/contact author: Matthew Adams, School of Applied Social Sciences, University of Brighton, Falmer, Brighton, BN1 9HP. Email: ma21@bton.ac.uk
} 
that media representations of male and female characters may well 'have serious effects on these children's gender role development and self-image' (Hamilton, Anderson, Broaddus and Young 2006: 758), an assertion substantiated by a wealth of research (Blake \& Maise 2008; Bradbard, Martin, Endsley \& Halverson 1986; Frawley 2008; Karniol \& Gal-Disegni 2009; Peterson \& Lach 1990; Tepper \& Cassidy 1999; Turner \& Gervai 1995; Whitehurst, Falco \& Lonigan 1998; Zemore, Fiske \& Kim 2000). This paper reports on a study which aimed to closely examine the nature of representations of a particular gendered social role - parenting - in one example of popular culture - young children's picturebooks.

Despite the growth and diversity of media aimed at children there remains a strong rationale for researchers interested in gender stereotyping to focus on the young children's picturebook. As an identifiable cultural form young children's picturebooks have been in existence since the mid-eighteenth century (Hunt 2009), and hence are firmly embedded in popular culture. Despite the growth in the range of media available to young children since the early days of picturebooks children's literature has maintained an audience and gained in artistic and literary credibility (Hunt 2009). This credibility is reflected in the recent creation of the role of 'children's laureate' by royal appointment in the UK, and various wellpublicised annual prizes globally. In more rudimentary measures, sales of children's books have increased their share of the overall volume of book sales in recent years (Noble 2010); in 200822.9 million preschool picturebooks were sold in the UK, an increase of $4.4 \%$ on the previous year, with a sales value of $98.9 \mathrm{~m}$ pounds sterling (Stone 2009).

The cultural importance of young children's picturebooks in particular is reflected in the significance they are increasingly granted in terms of early development and socialisation. It is a medium which has avowedly educational and interactive dimensions, playing an active role in early socialisation, including gender socialisation (Karrass and Braungart-Rieker 2005; Whitehurst, Falco and Lonigan 1988). In educational and developmental psychology there is an emphasis on the importance of shared reading (or reading aloud) from an early age in child development, in terms of language development (Whitehurst, Falco and Lonigan 1988; Raikes et al. 2006), but also emotional and personality development too (Blake and Maise 2008; Whitehurst and Lonigan 1998). This emphasis is also prevalent in parentcraft literature (e.g. raisesmartkid.com) and popular journalism (e.g. Randerson 2008). The established importance of early years exposure to gender stereotyping combined with the significance of picturebooks in the lives of children provides a rationale for a research emphasis on gender stereotyping in picturebooks aimed at pre-school children.

Despite a body of work analysing gender representations of main characters, often children, in children's books generally (Allen, Allen \& Sigler 1993; Clark, Guilmain, Saucier \& Tavarez 2003; Evans \& Davies 2000; Gooden \& Gooden 2001; Grauerholz \& Pescosolido 1999; Kolbe \& LaVoie 1981; Hamilton, Anderson, Broaduss \& Young 2006; Kortenhaus \& Demarest 1993; Peterson \& Lach 1990; Tepper \& Cassidy 1999), the study of parental figures is as yet relatively neglected. Other popular cultural forms featuring parenting have benefited from the attention of more sustained study, parentcraft literature in particular (Lazar 2000; Luke 
1994; Martin 2005; Sunderland 2000 2006). Neither has parenting representations in picturebooks featured as an object of study in the ever-growing sociological interest paid to fatherhood, despite an occasional emphasis on media and cultural forms therein (e.g. Dermott 2008; Hobson 2008; Lupton and Barclay 1997). We are drawn to parenting in particular because there is a great deal of debate over the extent to which the gendered nature of these roles has undergone change in recent years, and how far change is reflected in, or driven by, cultural representations of parenting (Daly 1993).

In contemporary Western societies where rigid gender roles have supposedly been brought into question, there is increased acknowledgment for the idea that, fathers, as well as mothers, should have a caring and nurturing relationship with their children (Bowers Andrews et al. 2004); that both mothers and fathers can be earners and carers; and that both boys and girls should be brought up encouraged to consider a shared role in caring for children as normal. For example a recent survey commissioned by the UK Government's Department for Business, Innovation and Skills found that over $90 \%$ of fathers surveyed with children aged five or under 'believe it is important that fathers have the option to take paid paternity leave', whilst $62 \%$ believe a father's 'relationship with their child will suffer if they are not at home after the baby is born' (cited by Fatherhood Institute 2010). Such ideas have become increasingly common-place, thus 'the emphasis now, from policy-makers as much as partners, is on a more involved role for fathers' (Williams 2008: 488), to the extent that being a 'caring and present father' has become 'a new ideal' (Johansson \& Klinth 2008: 42). Some research has suggested that this ideal translates into parenting practice to some degree as contemporary fathers spend more time with their children than did previous generations (Hall 2005), and that, despite an array of qualifying factors such as social structure, age and culture, 'a new generation of fathers [have] become concerned with developing closer relationships with their children' (Brannen \& Nilsen 2006: 347). Examples of associated social policy formation include the right to paternity leave and further unpaid parental leave, available to either parent, in the UK (directgov 2010). In a related development, absent fathers are now recognised as an important element of family breakdown and subsequently 'engaging fathers has become part of the agenda for many child welfare agencies' (Featherstone 2004: 312; e.g. National Fatherhood Initiative 2010).

Everyday realities are, as always, more complicated than ideals. Some research has questioned the extent to which 'involved fatherhood' has been translated into actual practices (Craig 2006; Jamieson 1999; Jarvis 1999; La Rossa 1998 1997; Speakman and Marchington 1999). Other studies accentuate ambivalence and variance in the actual experiences of parents, where mothers and fathers indicate attachments to different discourses and ideals that occupy divergent positions on a continuum stretching from traditional / conservative to egalitarian / progressive (Dana Shawnmatta and Carmenknudson-Martin 2006; O'Brien and Shemilt 2003; Williams 2008); and reflect varying degrees of practical care (Dermott 2003; Sullivan 2004). Further research questions the egalitarianism of 'involved fathering' discourses, arguing that these still situate fatherhood as a secondary and part-time role in which 'mothers continue to be positioned as primary parents' (Wall and Arnold 2007: 508; Lazar 2000; Sunderland 2000 2006). 
An important tributary to this debate is the extent to which 'involved fatherhood' is reflected in cultural representations of family life. Such a consideration is important in providing a barometer of change at the level of cultural representations, as reflected in the opening quote, but also because such representations are arguably vital in the socialisation of children and young people into gender roles and the maintenance and confirmation of gendered identities across the lifespan (Blake and Maise 2008; Bradbard, Martin, Endsley and Halverson 1986; Frawley 2008; Hamilton, Anderson, Broaddus and Young 2006; Karniol and Gal-Disegni 2009; Powlishta, Serbin, \& Moller 1993; Tepper and Cassidy 1999; Turner and Gervai 1995; Whitehurst, Falco and Lonigan 1998; Zemore, Fiske and Kim 2000). As noted above, existing work on children's books has tended to focus on child characters, finding consistent gender stereotyping despite the supposed societal shift away from traditional gender roles. Studies have tended to show that girl and women characters are generally under-represented in best-selling and award-winning books across a range of ages (e.g. Clark, Guilmain, Saucier and Tavarez 2003). Female characters, when present, were less likely to be shown outdoors or involved in adventure and active play (Hamilton, Anderson, Broaduss and Young 2006).

Studies of representations of parenting in this or any medium are much rarer, despite children's understanding of parental roles being seen as key to their own gender development and subsequent implications for wellbeing (Witt 1997). There are notable exceptions in related media such as advertising (Lupton and Barclay 1997) and childcare magazines (Sunderland 2000; 2006), and one study that draws on images of parents in a qualitative analysis of school reading books (Jackson and Gee 2005). The only quantitative study of representations of mothers and fathers in picturebooks to the author's knowledge is Anderson and Hamilton's (2005). These authors developed a coding instrument which was then used to analyse the representation of mothers and fathers in a sample of 'prominent' children's books. Their analysis revealed that in contrast to the underrepresentation of women and girls more generally, fathers were under-represented in their sample compared to mothers. When fathers did appear, they were portrayed as 'withdrawn and ineffectual parents' compared to mothers (2005: 145). In light of their insightful analysis, the present study has a developed a modified version of the coding instrument utilised by Anderson and Hamilton, and attempts to develop their analysis in a number of ways.

We have attempted to replicate the basics of their analysis (e.g. number of appearances of fathers and mothers) in a contemporary UK context, thus updating their findings, whilst making the sample more age-specific and populist, extending the scope of the instrument and refining a number of the categories. The changes made are intended to probe further the potential portrayal of mothers as nurturing and care-giving, and fathers as 'withdrawn and ineffective', if this primary distinction remained evident, in a novel sample. Our general hypothesis was that mothers and fathers would be represented as behaving in accordance with gender stereotypes in picturebooks aimed at very young children, and to a similar degree as that found in the earlier study of children's books more generally. More 
specifically, we hypothesised that in a contemporary UK sample of more narrowly defined and popular age-specific picturebooks: (1) fathers would be significantly less likely to appear and be mentioned than mothers; (2) that mothers would be more likely to be portrayed touching their children reflecting a rudimentary measure of nurturing; (3) mothers would be more likely to express any emotion (crying, happiness) than fathers. These points essentially reflect Anderson and Hamilton's hypotheses, though we took the opportunity to extend the range of emotions accounted for by the coding instrument (e.g. examples of smiling, laughing, encouraging, consoling, sadness, crying, exasperation, fear and worry).

However we made a number of additional hypotheses, reflecting the more detailed coding instrument and the intention to probe apparently stereotypical behaviours further. It was hypothesised that: (4) as well as appearing more often, mothers are more likely to appear with their children; (5) when they do appear, mothers would be more likely to be pictured in and around the home than fathers, and whether at home or not, more likely to be involved in domestic activities (e.g. cooking, cleaning) or childcare activities (e.g. bath time, bed time); (6) that mothers would be more likely to be involved in specific forms of touching, nurturing and functional, but not necessarily playful touching.

\section{METHOD}

\section{Sample}

Previous studies of stereotyping in children's books have mainly focused on prize-winning or prize-nominated books (Ly Kok and Findlay 2006; Gooden and Gooden 2001; Kolbe and LaVoy 1981; Roger et al. 2003). Prize lists such as Caldecott medal-winners and nominees essentially provide a convenience sample, with no specific emphasis on breadth of readership. Earlier studies, particularly, though not exclusively, those which have focused on prize-winning books, have also tended to overlook the variety of ages the books within their samples have been aimed at, and the subsequent variation in book layout, text-image ratio, and likely reading context. ${ }^{2}$ Consequently our intention was to draw from a sample of books more widely circulated within the UK, whilst honing in on a sample aimed at a particular age-range. Whilst there is significant value in a broad and non-specified sample, a sharper focus on a particular age-category, with a larger sample of that category, has greater chance of being representative of the type of book that is read to/with young children.

Our sample was based on best-selling pre-school children's picturebooks in the UK in one year (2008), as determined by Nielsen BookScan, a company which collects the retail sales information from point of sale systems across the globe (Nielsen BookScan 2010). The

\footnotetext{
${ }^{2}$ The Caldecott medal criteria allows for books aimed at children up to fourteen years old, is restricted to authors who are residents or citizens of the United States, and only books which were first or simultaneously published in the United States in the previous year (American Library Association 2009).
} 
information provided allowed us to focus in on picturebook fiction in the $0-5$ years category ('preschool') in establishing our initial sample, which consisted of 750 books. Sales figures on the list ranged from 280000 in the UK in one year at the top to 2000 at the bottom. A sub-sample was then selected based on the single criteria that they contained any representations of parents; all texts which had no image or reference to parents were excluded. From this sub-sample of approximately 160 books a random sample of 60 were selected for the present analysis. A power analysis was carried out using the GPower statistical programme (Faul et al. 2009). This revealed that, with an effect size of 0.5 , this sample size would be sufficient to generate a power 0.80 for the selected data analysis.

\section{Procedure}

\section{Coding Instrument Design}

Two of the authors (__ and _ _ piloted an adapted version of the coding instrument used in Anderson and Hamilton's study (2007). Based on the author's initial reading of children's picture books, the instrument was edited and refined before further preliminary testing. Members of the a group of academic staff and researchers interested in culture, consumption and identity based the then read a sample of eight books, completing copies of the preliminary coding sheets. The discussed queries and issues with the coding process. The authors modified the instrument in light of this discussion, and then produced a revised coding sheet and coding instructions. The process was then repeated: the revised coding sheet was used by the to code another sample, followed by further discussion and revision until the research team were confident that the sample was being coded consistently by all readers. Clear instructions on coding were drawn up and each book in the final random sample was then coded independently by two of the authors (_ and __).

\section{Instrument Contents}

The coding instrument was developed with the aim of establishing whether or not there are significant differences between mothers and fathers in terms of the number of appearances of parents, type of setting parents appeared in, who parents appeared with, the range of activities they were involved in, their emotional expression and mentions of parents in the text. The details of the coding instrument took Anderson and Hamilton's 43 items as a point of departure (2005). Scoring involved frequency counts per book - recording counts as individual marks which were then summed. As well as basic counts of number of appearances, the instrument differentiated between who parents appeared with (e.g. alone, with other parent, with male or female child or children), who mentioned parents (e.g. girl, boy, other), types of touching activity (e.g. carrying, hugging, kissing), emotional expression (e.g. happy, sad, angry), the specific setting of each parent appearance (e.g. at home, workplace, at or on way to school/nursery). The instrument offered further differentiation of 'nurturing activity' to incorporate finer distinctions between what Anderson and Hamilton described as more or less 'involved' touching (e.g. play contact), and incorporated other nurturing activity which might not involve explicit touching (e.g. 
bath-time, bed-time). The instrument contained 160 items, some of which are grouped together for the purposes of analysis here (see table 1).

\section{Data Analysis}

In order to ensure the accuracy and integrity of the dataset, a set of frequency checks were carried out. To supplement this, $10 \%$ of the dataset were checked in order to test whether the number of data entry errors was sufficiently low. It was decided that, should the number of errors fall below the $1 \%$ level then the data set was sufficiently accurate to proceed to analyses. The $1 \%$ level of acceptable error count was 39 . Our actual recorded error count was 16 and so it was considered that the data entry process was accurate. The SPSS 16 statistical package was used to perform the analyses in this study. Strong rater agreement in research contexts is important because it demonstrates that researchers and practitioners can consider the same case information similarly (Murrie et al. 2009). An Intraclass correlation coefficient was generated in order to test interrater reliability of the coding instrument. This has been suggested as an appropriate analysis for interrater reliability (Gliner \& Morgan 2000) and was used in order to provide an account of the reliability between Rater A and Rater B. A series of paired t-tests were then performed in order to examine potential variability in parental gender representations in the selection of children's books selected for the study. All pairwise comparisons were subject to appropriate Bonferonni corrections in order to minimise the probability of generating a Type-I error. However with the additional risk of generating a Type II error given the relatively small sample size, we refer to findings at $\mathrm{P}<0.01$ as significant.

\section{RESULTS}

The ICC analyses for observations between raters on scores for the coding instrument was 0.957 . This high coefficient represents an excellent standard of interrater reliability (Aronson et al 2002). Hinojosa and Kramer (1998) suggest specifically that an ICC of 0.85 be considered an acceptable level of interrater reliability. Hence the reliability of this instrument is clearly well beyond this convention of acceptability. A series of $t$ tests showed that there were significant differences in a number of key parental representations in the texts, offering strong support for most of our hypotheses. Table 1 illustrates that in books that included images of parents, mothers are significantly more likely to appear in the sample of children's books than fathers, supporting our first hypothesis (1). Mothers were also significantly more likely to be mentioned either by a child or by the narrator than fathers - mothers were more than twice as likely to be mentioned in the text - again supporting our first hypothesis. In terms of hypothesis (2) that mothers would be more likely to be portrayed touching their children, reflecting a rudimentary measure of nurturing, it was found that they were significantly more likely to be portrayed touching their child than fathers were. Our third hypothesis (3) was that mothers would be more likely to express any emotion (crying, happiness) than fathers. The findings indicate that mothers were significantly more likely to display all emotions, both positive and negative. 
Invisible or involved fathers?

Table 1: T-tests comparing a series of parental gender representations in preschool childrens' picturebooks

\begin{tabular}{|c|c|c|c|c|}
\hline & Mother M (SD) & Father M (SD) & $t$ & $p$ \\
\hline \multicolumn{5}{|l|}{ Appearances } \\
\hline Total number of appearances & 7.317 (5.809) & $4.483(5.622)$ & 3.492 & 0.001 \\
\hline Number of mentions & $6.000(8.563)$ & $2.450(4.139)$ & 3.275 & 0.002 \\
\hline One parent with son (a28) & $1.817(2.652)$ & $0.633(1.667)$ & 3.368 & 0.001 \\
\hline One parent with daughter (a30) & $1.312(2.943)$ & $0.300(0.997)$ & 2.630 & 0.011 \\
\hline One parent alone (a27) & $0.883(1.923)$ & $0.450(1.307)$ & 1.573 & 0.121 \\
\hline Parent in/outside the home (a16) & $4.050(4.556)$ & $2.483(3.530)$ & 2.804 & 0.007 \\
\hline \multicolumn{5}{|l|}{ Contact } \\
\hline Touching child total & $2.167(3.701)$ & $0.933(2.557)$ & 2.899 & 0.005 \\
\hline Play contact (tickling, swinging) & $0.117(0.783)$ & $0.050(0.387)$ & 0.587 & 0.560 \\
\hline $\begin{array}{l}\text { Functional contact (carrying, } \\
\text { piggyback) }\end{array}$ & $1.067(2.667)$ & $0.150(0.444)$ & 2.622 & 0.011 \\
\hline $\begin{array}{l}\text { Explicit nurturing contact } \\
\text { (hugging/cuddling, kissing) }\end{array}$ & $0.333(0.795)$ & $0.133(0.536)$ & 1.725 & 0.090 \\
\hline \multicolumn{5}{|l|}{ Emotional expression } \\
\hline $\begin{array}{l}\text { positive (smiling, consoling, } \\
\text { affectionate) }\end{array}$ & $2.533(2.879)$ & $1.383(2.026)$ & 3.440 & 0.001 \\
\hline $\begin{array}{l}\text { Negative emotion (sad, angry, } \\
\text { scared, worried) }\end{array}$ & $1.667(2.297)$ & $0.767(1.661)$ & 3.551 & 0.001 \\
\hline \multicolumn{5}{|l|}{ Other activity } \\
\hline $\begin{array}{l}\text { Child care related (not involving } \\
\text { touching: bathtime, reading to, } \\
\text { bedtime routine, taking to } \\
\text { nursery/school) }\end{array}$ & $1.517(3.122)$ & $1.183(2.825)$ & 1.064 & 0.292 \\
\hline $\begin{array}{l}\text { Other domestic activity } \\
\text { (shopping, any housework) }\end{array}$ & $0.83(1.617)$ & $0.100(0.354)$ & 4.182 & 0.000 \\
\hline Disciplining acts & $0.050(0.220)$ & $0.050(0.220)$ & 0.000 & 1.000 \\
\hline
\end{tabular}

$N=60$ 
The results offered partial support for the hypothesis (4) that as well as appearing more often, mothers are more likely to appear with their children. More specifically, mothers were significantly (almost three times) more likely to appear with their son(s) than fathers. Although the level of significance for the difference between mother and father appearances with their daughter(s) falls just outside of our new Bonferroni significance level $(p=0.011)$, this result should be borne in mind as potentially interesting and worth further investigation. The lower mean number of appearances of either parent with daughters may reflect the relative dearth of representations of girl characters reported elsewhere (e.g. Hamilton, Anderson, Broaduss and Young 2006) though this was not analysed in the present study. Appearances of parents alone were also analysed in the present study and it was hypothesized that fathers would be more likely to appear alone, reflecting traditional stereotypes of fathers being more independent (of family and the home). In fact mothers were almost twice as likely to appear alone than fathers, though there was no significant difference possibly due to the scarcity of such appearances for both sexes.

The related hypothesis (5) that when they do appear mothers would be more likely to be pictured in and around the home than fathers was upheld: compared to fathers, mothers were significantly more likely to feature in and around the home. It was additionally hypothesised that regardless of physical contact, mothers, compared to fathers, would be more often portrayed as involved in domestic and childcare activities. It was found that mothers were significantly more likely to appear involved in domestic activities than fathers. However, the hypothesis was partially refuted in that there were no significant differences in activities grouped together as childcare. In terms of our final hypothesis (6), we attempted to differentiate between 'nurturing', 'functional and 'playful' contact, hypothesising that whilst mothers would be more likely to be portrayed in nurturing contact, fathers may be more likely to be involved in playful contact, thus reflecting traditional gender stereotypes within the general category of 'touching'. This hypothesis was not upheld. Despite being significantly less likely to appear touching their children overall, fathers were not less likely to be portrayed involved in nurturing contact (hugging, cuddling, kissing); nor were they more likely to be involved in playful contact (tickling, swinging). Differences between mothers and fathers on functional contact lie just beyond significance.

\section{DISCUSSION}

This current research displayed a number of methodological strengths, particularly in comparison with Anderson and Hamilton's (2005) original work. As far as we are able to ascertain, Anderson and Hamilton (2005) used a considerable number of pairwise T-tests without the application of appropriate Bonferroni corrections to reduce the considerable probability of generating a Type-I error. The calibration of significance at $p<0.01$ in the present study represented an attempt to balance the respective probabilities of making a Type-I or Type-II error. As such we believe this minimised the potential for our analysis to present a spurious result. Moreover while Anderson and Hamilton's (2005) study included key measurement criteria as regards parental gender roles, it is our contention that a number of their criteria would benefit from further specificity. The instrument used in the 
present study, through a more detailed array of measurement items, represented an attempt to reflect the nuanced and sophisticated ways in which parental identities are configured in children's picturebooks.

There are numerous limitations to the present study. The sample was reflective of high sales but this does not guarantee wide readership nor inform us about the context in which they are read. In terms of the first point the initial intention was to supplement sales figures with UK library borrowing figures. However, at the time of data collection, borrowing figures were not detailed or extensive enough to meaningfully integrate the data into a sample of best-sellers. Future research might benefit from advances in library technologies, or a focus on the micro-settings of individual libraries. Whilst we could not claim that all these books were being read, or that they were the only books being read, in practical terms we were confident that our sample was representative of books with a wide circulation compared to a focus on prize-winning texts, and therefore suitably comprehensive. There are clear limitations to generalizability in terms of the UK focus but this is considered here to be an interesting corrective to the US-focus of much work. In terms of the second point there is no doubt that further qualitative (e.g. semiotic) analysis and studies of the interactive context in which the meanings of children's picturebooks are read is necessary.

In contrast to previous studies we narrowed our initial sample according to whether they contained any representations of parents, excluding all texts which had no image or reference to parents. Although time-consuming (unless it was obvious from the cover, publicity or title, the only way to do this was to read the books in situ), this process further strengthened our confidence that the remaining total sample of 160 books reflected an advance on previous research in terms of representativeness of young children's picturebooks featuring images of parents ${ }^{3}$. Though the eventual sub-sample of 60 books could be deemed small in size, the extended coding instrument allowed for thorough scrutiny, blurring the boundaries between qualitative and quantitative content analysis, whilst the GPower statistical power analysis showed that the sample size was sufficient.

The coding instrument was limited in that the majority of our coding items were directed towards pictures rather than text; though there were some important findings in relation to the latter. The rationale for this emphasis lies in part on the researcher's assumptions about the attentional capacities of the child reader; which we assumed to be directed more towards pictures at pre-school age. This assumption appears to be supported by recent evidence from eye movement monitoring studies, which demonstrate that preschool children spend much more time exploring images than text, regardless of variations in

\footnotetext{
${ }^{3}$ Interestingly the proportion of books featuring images of parents in this sample is approximately $21 \%$; much lower than Anderson and Hamilton's final sample of books including parental figures (2005), which was almost $70 \%$ of their original sample of various best-seller lists and prize-winners. This might reflect the different ways each study collected its sample, the nature of the sample, or the different national contexts - we can only speculate.
} 
layout: on average they spent eighteen times longer looking at illustrations compared to text (Evans and Saint-Aubin 2005). Still, future quantitative or qualitative research focusing on a textual analysis, particularly in conjunction with imagery, would provide interesting additional data.

Any quantitative coding instrument is inevitably limited in that it embodies an essentially arbitrary set of precepts and a different instrument and focus may have found different results. However the high interrater reliability of the coding instrument suggests that this tool is a viable instrument with which to measure gendered representations of parenthood for future research. It should also be noted that while differences may have been significant, in some cases the actual frequencies of either parent fulfilling the category were very small. This suggests that future refinements of the coding instrument items are possible. The process of quantitative content analysis itself offers an abstracted portrayal of the interrelated dynamics of stereotypes found in picturebooks. For example the placing of parents in relation to each other, their positioning in relation to an overall narrative, associated descriptive terms, and the nuances of relationships between parents, children and others of both sexes often remain opaque; subsequently a strong case could again be made for further qualitative content or narrative analysis to provided a thicker description of the portrayals at play. That said, quantitative content analysis proved to be particularly suitable for grasping the general patterns of gender stereotyping of parents that cannot be revealed by anecdotal readings or case studies.

Furthermore, building on previous quantitative work and our own pilot studies allows for the development of previous categories and attention to detail which blurs the qualitative/quantitative distinction to some extent. In fact Jackson and Gee's qualitative analysis of constructions of gender in early school reader illustrations across 50 years highlighted the predominance of images of mothers hugging and kissing a child, and of mothers as child-focused and domestic, in or away from home: 'mother served, watched children, cared for children and provided food' (2005, page). Our quantitative content analysis in effect incorporates what might originally be qualitative insights such as these into more nuanced comprehensive frequency counts. Further qualitative analysis is necessary to further unpack the subtleties of the interrelated discourses of femininity and masculinity in play.

The results offer strong support for our overall hypothesis that mothers and fathers would be represented as behaving in accordance with traditional gender stereotypes. To our minds, fathers remain as 'invisible' in terms of basic and foundational variables analysed as they did in Anderson and Hamilton's study (2005), even in relation to novel items. Fathers were significantly less likely to appear than mothers, to be mentioned by characters or narrators, to appear with their children, to appear in or around the home, to be involved in physical contact with them, to be portrayed as expressing any emotion, or to be involved in any kind of domestic activity. Assuming that the latest publication date of books in Anderson and Hamilton's sample was 2004, approximately one third of our total sample was 
published after that date. Does our evidence thus suggest that nothing has changed in that time period or in the shift of emphasis to the UK and to a more age-focused sample? There are additional findings which run contrary to our hypotheses. We attempted to differentiate 'touching' activity into subcategories that might reflect gender stereotypes. The fact that fathers were less likely, but not significantly so, to appear engaged in stereotypically maternal touching (hugging and kissing) perhaps suggests a portrayal of fatherhood which concedes some ground to the 'involved' ideal. The finding that mothers are significantly more likely to be portrayed carrying out domestic activities, but not those specifically defined as routine childcare activity may support this observation. The finding that fathers were not significantly more likely to appear in stereotypically paternal 'play' touching (tickling and swinging) could also be read as a further indicator of a loosening of the grip of traditional stereotypes.

These additional findings running counter to our initial hypotheses and perhaps suggest some movement away from invisibility and towards the ideal of involved fatherhood outlined at the beginning of this paper. Perhaps these findings reflect the 'uneven' nature of changes in gender representation and broader patterns of actual parenting, as McNay states here:

If there can be said to have been any attenuation of conventional notions of masculinity and femininity in the last 30 years or so, it needs to be thought of as a much more piecemeal, discontinuous affair arising from the negotiation of discrepancies by individuals in their movement within and across fields of social action.

(McNay 1999: 110)

Before we embrace even patchy progress in parental representations however, the limitations of this study require further consideration. Although attempts have been made here to look into greater detail at established themes in the content analysis of gender stereotypes, we do not profess total confidence in our own attempts at categorisation. It may be that different activities could be grouped under the heading 'childcare' and 'domestic activity' perhaps, from which different results might follow. It is possible that our categorisation reflected the subjective and partial nature of differentiating between types of touching in this way. If partially progressive representations are identifiable, further research is needed to discover whether this reflects change over time or other peculiarities of the sample.

The social and political implications of our findings are necessarily ambivalent. In her analysis of representations of parenting in government advertising, Lazar pinpoints the threefold political nature of representative practices in terms of relatedness, modes and power dynamics: The issue of relatedness asks the question 'who is represented (or not) in what ways in relation to the other?'; modes of representation focuses attention on the linguistic and non-linguistic resources deployed in the process of representation. The two combine in the third political consideration - an analysis of the power dynamics at play in representational practices. Despite the difference in subject matter and methodological 
approach - a discourse analysis of a government advertising campaign in Singapore, Lazar's elaboration of power dynamics relates directly to the implications of the representational practices found in children's picture books. Like Lazar we must ask 'what does the representation/non-representation tell us about the (changing or unchanging) contemporary balance of power between, in this case, women and men in the domain of parenthood? Whose interests are served by it, and whose suppressed' (Lazar 2000: 374).

The contemporary critical study of gendered parent identities is rightly concerned with asymmetry in terms of the benefits proffered for men who continue to be more 'able' to escape parental responsibility, have autonomous leisure time, and pursue a career. For women, activities related to established stereotypical gender roles appear to persist, with mothers performing more housework than fathers even when both work full-time (Bond, Thompson, Galinsky and Prottas); including 'new' chores such as recycling (Oates and Macdonald 2006); though other research has identified moves towards greater equality in the division of domestic labour (Sullivan 2000). More generally, huge changes in labour markets over the last 30 years and the growing disparities between income and expenditure (ie property prices) for many people have seen more and more women work in full time jobs whilst also shouldering this burden of childcare (Ericson 2008). This dual role or 'double burden' has led some authors to suggest that a growing number of women are effectively working a 'second shift' at home (Hochschild and Machung 1997), which may be seriously impacting on many women's wellbeing (Floderus et al. 2009; Marshall 2009). Clearly, stereotypically 'traditional' gender representations have a part to play in reinforcing this state of affairs as somehow normal.

However, a straightforward assertion that the inequity of gendered stereotype representations benefits one party at the expense of another should also be approached with caution. Both men and women make gains in egalitarian relationships, whilst the perpetuation of traditional gender stereotypes undoubtedly indicates that 'the meanings of being a woman and a mother available to child readers through the illustrations are highly restricted', we should be wary of positioning the converse framing of men and fathers as 'active and agentic' (Jackson and Gee 2005: 124). It could be argued that by presenting fathers as uninvolved and absent parents in cultural scripts, men and developing boys are being encouraged to miss out on 'the privilege and emotional development that may come from increased contact and work with children' (Hearn 1994: 48); not least those that might be in their care. The present study builds on previous work to suggest that cultural representations of mothers and fathers continue to perpetuate problematic stereotypes but unevenly. Consequently it could be posited that the 'slowness' of actual changes in fatherhood practices may partially reflect a 'lack of exposure to appropriate paternal role models' (Daly 1993: 510). If we are to avoid perpetuating a situation where 'the choice of being an active father is jeopardized by evoking a very basic conflict in the symbolic universe of masculinity' (Hojgaard 1997: 245), changes in that symbolic universe need to be more forthcoming than the contemporary truism of involved fatherhood suggests, despite some ground being gained. 


\section{Conclusion}

In sum, we extended and refined findings indicating an imbalance in representations of mothers and fathers, in which fathers are significantly under-represented in general, and in terms of physical contact with their children. They remain 'invisible' though the subtleties of our results suggest some acknowledgment of fatherhood as involved in childcare activity. In reflecting on the results of their content analysis, Anderson and Hamilton argue that 'a risk of stereotypical portrayals is that they may socialize children and parents at important periods in their development, when parents identify their role in the spectrum from affectionate caregiver to deadbeat absentee, and when children form their expectations of parents' (2005: 150). The present study analysed a sample more sharply focused on books targeted at preschool children, an age which education psychology suggest is when children are most susceptible to stereotypes, when they are developing their very sense of the reality of the world of the around them (Powlishta, Serbin, \& Moller 1993). Of course picturebooks are read with adults who actively negotiate meanings in communication with children, in a cultural context saturated by a plethora of media portrayals of every aspect of reality so caution is vital in making claims about the effect of stereotypical representations upon children - the traffic between is likely to be fraught with structural, situational and idiosyncratic translations. However, if representations of parents in children's picturebooks are a reflection of cultural norms to anything approaching the extent suggested by the opening quote, obstacles to egalitarian parenthood remain, and the quality of life of children and parents of both sexes are truncated as a result.

\section{References}

Allen, A. M., Allen, D. N., \& Sigler, G. (1993). Changes in sex-role stereotyping in Caldecott Medal Award Picture Books 1938-1988. Journal of Research in Childhood Education, 7, 6773.

American Library Association (2009). Caldecott Terms \& Criteria'. Available at http://www.ala.org/ala/mgrps/divs/alsc/awardsgrants/bookmedia/caldecottmedal/caldeco ttterms/caldecottterms.cfm [last accessed 08/04/10].

Anderson, D.A. \& Hamilton, M. (2005). Gender role stereotyping of parents in children's picture books: The invisible father. Sex Roles, Vol. 52(3/4), 145-151.

Aronson, N., Alonso, J., Burnam, A., Lohr, K.N., Patrick, D.L., \& Perrin, E. (2002). Assessing health status and quality of life instruments: Attributes and review criteria. Quality of Life Research, 11 193-205.

Blake, J. \& Maiese, N. (2008). 'No fairytale... The benefits of the bedtime story' The Psychologist Vol. 21(5) 386-88.

Bond, J.T., Thompson, C., Galinsky, E., \& Prottas, D. (2002). Highlights of the national study of the changing wokforce. New York, NY: Families and Work Institute. 
Bowers Andrews, A., Luckey, I., Bolden, E., Whiting-Fickling, J. \& Lind, K.A. (2004). Public perceptions about father involvement results of a statewide household survey. Journal of Family Issues, Vol. 25(5), 603-633.

Brannen, J. \& Nilsen, A. (2006). From fatherhood to fathering: Transmission and change among british fathers in four-generation families. Sociology, Vol. 40(2), 335-352.

Clark, R., Guilmain, J., Saucier: K., \& Tavarez, J. (2003). Two steps forward, one step back: The presence of female characters and gender stereotyping in award-winning picture books between the 1930s and the 1960s. Sex Roles, 49, 439-449.

Craig, L. (2006). Does father care mean fathers share? A comparison of how mothers and fathers in intact families spend time with children. Gender \& Society, Vol. 20(2), 259-281.

Daly, K. (1993). 'Reshaping Fatherhood: Finding the Models' Journal of Family Issues Vol. 14(4)p. 510-30

Dana Shawnmatta, W. \& Carmenknudson-Martin, Z. (2006). Father responsivity: Couple processes and the co-construction of fatherhood. Family Process, Vol. 45(1) 19-37.

Dermott, E. (2008). Intimate fatherhood: A sociological analysis. London: Routledge.

Dermott, E. (2003). The 'intimate father': Defining paternal involvement. Sociological Research Onlien, 8(4). Available at http://www.socresonline.org.uk/8/4/dermott.html. [Last accessed 10/06/10].

directgov (2010). Statutory paternity leave. Available at http://www.direct.gov.uk/en/Parents/Moneyandworkentitlements/WorkAndFamilies/Pater nityrightsintheworkplace/DG 10029398 [last accessed 03/06/10].

Ericson, M. (2008). Equalization of paid working hours in the dual-earner household: Does it increase women's double burden? Working Papers in Economics, No. 291. Göteborg University. Available at http://hdl.handle.net/2077/9678 [last accessed 4th June 2010]

Evans, M.A. \& Saint-Aubin, J. (2005). What children are looking at during shared storybook reading evidence from eye movement monitoring' Psychological Science, Vol. 16(11), 91320.

Evans, L., \& Davies, K. (2000). No sissy boys here: A content analysis of the representation of masculinity in elementary school reading textbooks. Sex Roles, 42, 255-270.

Fatherhood Institute, (2010). Government campaign reminds dads of their rights at work. Available at http://www.fatherhoodinstitute.org/index.php?id=10\&clD=1045 [last accessed 03/06/10].

Faul, F., Erdfelder, E., Buchner, A., \& Lang, A.-G. (2009). Statistical power analyses using G*Power 3.1: Tests for correlation and regression analyses. Behavior Research Methods, 41, 1149-1160.

Featherstone, B. (2004) Fathers matter: A research review. Children \& Society Vol. 18, 312319. 
Floderus, B., Hagman, M., Aronsson, G., Marklund, S. \& Wikman A. (2009). Work status, work hours and health in women with and without children' Occupational and Environmental Medicine, 66, 704-710.

Frawley, T. J. (2008). Gender schema and prejudicial recall: How children misremember, fabricate, and distort gendered picture book information. Journal of Research in Childhood Education, 22, 291-303.

Gliner, J.A. \& Morgan, G.A. (2000). Research methods in applied settings: An integrated approach to design and analysis. Mahwah, NJ: Lawrence Erlbaum Associates.

Gooden, A. M., \& Gooden, M.A. (2001). Gender representation in notable children's picture booksp. 1995-1999. Sex Roles, 45, 89-101.

Grauerholz, E. and Pescosolido, B.A. (1989). Gender representation in children's literaturep. 1900-1984. Gender \& Society, Vol. 2 (1)p. 113-125.

Hall, S.S. (2005). Change in paternal involvement from 1977 to 1997: A cohort analysis. Family and Consumer Sciences Research Journal, Vol. 34 (2), 127-139.

Hamilton, M. C., Anderson, D., Broaddus, M., \& Young, K. (2007). Gender stereotyping and under-representation of female characters in 200 popular children's picture books: A twenty-first century update. Sex Roles, 55, 757-76.

Hearn, J. (1994). Research in men and masculinities: Some sociological issues and possibilities. Journal of Sociology, Vol. 30(1), 47-70.

Hinojosa, J, \& Kramer: (1998). Occupational therapy evaluation: Obtaining and interpreting data. Bethesda, MD: The American Occupational Therapy Association.

Hobson, B. (ed.) (2008). Making men into fathers: Men, masculinities and the social politics of fatherhood. London: Sage

Hochschild, A. and Machung, A. (1997, $2^{\text {nd }}$ ed.). The Second shift: Working parents and the revolution at home. London: Paitkus.

Hojgaard, L. (1997). 'Working fathers - caught in the web of the symbolic order of gender'. Acta Sociologica, Vol. 40, 245-261.

Hunt: (2009). The world in pictures. In Hallam, S. (ed.) Illustrated Children's Books. Pp. 8-26. London: Black Dog Publishing.

Johansson, T. \& Klinth, R. (2008) Caring fathers: The ideology of gender equality and masculine positions. Men and Masculinities, Vol. 11 (1), 42-62.

Karniol, Rachel; Gal-Disegni, Michal. 2009 The impact of gender-fair versus genderstereotyped basal readers on 1st-grade children's gender stereotypes: a natural experiment The Free Library (June, 22), http://www.thefreelibrary.com/The impact of gender-fair versus gender-stereotyped basal readers on ...-a0204681841 (accessed May 18 2010) 
Karrass, J. \& Braungart-Rieker, J.M. (2005). Effects of shared parent-infant book reading on early language acquisition. Applied Developmental Psychology, 26,133-148.

Kolbe, R., \& LaVoie, J. C. (1981). Sex-role stereotyping in preschool children's picture books. Social Psychology Quarterly, 44, 369-374.

Kortenhaus, C. M., \& Demarest, J. (1993). Gender role stereotyping in children's literature: An update. Sex Roles, 28, 219-232.

La Rossa, R. (1988). Fatherhood and social change. Family Relations, Vol. 37, 451-457.

La Rossa, R. (1997). The modernization of fatherhood: A social and political history. Chicago: University of Chicago Press.

Lazar, M. M. (2000). Gender, discourse and semiotics: The politics of parenthood representations. Discourse and Society, Vol. 11(3), 373-400.

Lees, S. \& Senyard, J. (1985). Taste and table manners: Class and gender in children's books of the 1950s. Journal of Sociology, Vol. 21(2), 174-193.

Luke, C. (1994). Childhood and parenting in popular culture. Journal of Sociology, Vol. 30(3), 289-302.

Lupton, D. and Barclay, L. (1997). Constructing fatherhood: Discourses and experiences. London: Sage.

Ly Kok, J., \& Findlay, B. (2006). An exploration of sex-role stereotyping in Australian awardwinning children's picture books. The Australian Library Journal, 55, 248-261.

Marshall, K. (2009). The family work week. Perspectives on Labour and Income, Vol. 10 (4), 5-13. Available at http://www.statcan.gc.ca/pub/75-001x/2009104/pdf/10837-eng.pdf [last accessed 5/06/10].

Martin, K. (2005). William wants a doll, can he have one? Feminists, child care advisors, and gender-neutral child rearing. Gender \& Society, Vol. 19(4), 456-479.

Mayo, E. \& Nairn, A. (2009). Consumer Kids. How big business is grooming our children for profit. London: Constable.

Murrie, DC, Boccaccini, MT, Turner, DB, Woods, C, \& Tussey, C, (2009). Rater (dis)agreement on risk assessment measures of sexually violent predator proceedings. Psychology, Public Policy \& Law, 15(1) 19-53.

National Fatherhood Initiative (2010). Available at http://www.fatherhood.org/ [last accessed 03/06/10].

Nielsen BookScan (2010). Available at http://www.nielsenbookscan.co.uk [last accessed 11/05/10]. 
Noble, F. (2010). Every picture(book) tells a story: green shoots are emerging in the picturebook genre. The Bookseller, 5420, 27.

Oates, C.J. \& McDonald, S. (2006). Recycling and the domestic division of labour: is green pink or blue? Sociology, Vol. 40(3), 417-33.

O'Brien, M. \& Shemilt, I. (2003). Working fathers: Earning and caring. London: Equal Opportunities Commission.

Peterson, S. B., \& Lach, M. A. (1990). Gender stereotypes in children's books: Their prevalence and influence on cognitive and affective development. Gender and Education, 2, 185-197.

Powlishta, K. K., Serbin, L. A., \& Moller, L. C. (1993). The stability of individual differences in gender typing: Implications for understanding gender segregation. Sex Roles, 29, 723-737.

Raikes, H., Pan, B. A. \& Luze, G. (2006). Mother-child bookreading in low-income families. Child Development, 77, 924-953.

Randerson, J. (2008) 'Benefits of bedtime reading' The Guardian newspaper, Tuesday 13 May 2008. Available at http://www.guardian.co.uk/education/2008/may/13/schools.uk4 [last accessed 10/06/10].

Speakman, S. \& M. Marchington (1999). Ambivalent patriarchs, breadwinners and housework. Work Employment \& Society, 13(1), 83-105.

Stone: (2009). Pre-school sector picture perfect: Philip Stone discovers a buoyant picture book market, with many books enjoying an anniversary in 2009. The Bookseller 5386p. 27.

Sullivan, O. (2004). Changing gender practices within the household: A theoretical perspective. Gender \& Society, Vol. 18(2) 207-222.

Sullivan, O. (2000). The division of domestic labour: twenty years of change? Sociology, Vol. $34(3), 437-456$.

Sunderland, J. (2000). Baby entertainer, bumbling assistant and line manager: discourses of fatherhood in parentcraft texts. Discourse and Society, Vol. 11(2), 249-274.

Sunderland, J. (2006). 'Parenting' or 'mothering'? The case of modern childcare magazines. Discourse \& Society, Vol. 17(4), 503-527.

Tepper, C. A., \& Cassidy, K. W. (1999). Gender differences in emotional language in children's picture books. Sex Roles, 40, 265-280

Wall, G. and Arnold, S. (2007). How involved is involved fathering? An exploration of the contemporary culture of fatherhood. Gender \& Society, Vol. 21(4), 508-527.

Whitehurst, G.J., Falco, F.L. \& Lonigan, C.J. (1988). Accelerating language development through picture book reading. Developmental Psychology, 24, 552-559.

Whitehurst, G.J. \& Lonigan, C.J. (1998). Child development and emergent literacy. Child Development, 69, 848-872. 
Invisible or involved fathers?

Williams, S. (2008). What is fatherhood? Searching for the reflexive father. Sociology Vol. 42(3), 487-502.

Witt, S.D. (1997). Parental influence on children's socialization to gender roles. Adolescence, Vol. 32(126), 252-59.

Zemore, E. S., Fiske, T. S., \& Kim, H. (2000). Gender stereotypes and the dynamics of social interaction. In T. B. Eckes \& H. M. Trautner (Eds.), The developmental social psychology of gender (pp. 207-241). Mahwah, NJ: Erlbaum. 